\title{
An improved method for estimating changes in whole-body fat and protein mass in man
}

\author{
BY P. R. MURGATROYD AND W. A. COWARD \\ MRC Dunn Clinical Nutrition Centre, 100 Tennis Court Road, Cambridge CB2 1QL
}

(Received 16 February 1989 - Accepted 24 April 1989)

\begin{abstract}
Sequential measurements of body density or total body water yield inaccurate estimates of body composition change unless the proportions of protein, water and mineral in lean tissue remain constant. Since rates of change of bone mass in adults are likely to be small compared with those of fat or protein mass, volume and total body water measurements can be combined in a three-compartment model to estimate fat and protein changes assuming constant mineral mass. This new model minimizes the bias inherent in estimates of fat or protein changes made from separate density or total body water measurements.
\end{abstract}

Whole-body fat mass: Whole-body protein mass

Assessments of body composition generally consider the body in terms of protein, mineral, water and fat compartments, each of which has distinct physical properties. Most composition estimates, however, are made in terms of weight and only one additional measurement, such as density or total body water. Consequently, to estimate the size of one compartment, stable relationships must be assumed to exist between the remaining three compartments. Siri (1961) has shown that uncertainty in the relative proportions of protein, mineral and water in the fat-free body far exceeds analytical imprecision as the major source of uncertainty in estimates of total body fat made from either densitometry or total body water measurements. He did, however, demonstrate that the use of weight, density and total body water measurements in a three-compartment model could improve the precision of fat estimation. This model has, surprisingly, been neglected for too long.

In many situations the determination of the absolute amount of a body constituent is less important than the measurement of changes. Changes in composition resulting from surgery, infection and dietary manipulation are frequent topics for investigation. However, it is barely conceivable that when changes in body-weight occur, only one tissue is gained or lost. An assumption of constant composition or hydration of the fat-free body in these circumstances, therefore, leads not simply to uncertainty but to error in the estimation of fat change. The only component of body composition which can arguably be regarded as unaltered by short- or medium-term composition change is skeletal mineral. If this assumption is accepted, three variable components, protein, fat and water, remain. Thus three independent, high precision measurements, body-weight, body volume and total body water, can be used to develop a new model for elucidating changes in fat or protein mass with a confidence determined by the precision of the physical measurements. Formulas for estimating fat and protein changes are now derived. 


\section{METHOD}

Consider a body of volume $V$, weight $W$ and density $d$ in four components whose weights, volumes and densities are identified as:

$\begin{array}{lccc} & \text { Weight } & \text { Volume } & \text { Density } \\ \text { Fat } & f & F & d_{\mathrm{f}} \\ \text { Protein } & p & P & d_{\mathrm{p}} \\ \text { Water } & t b w & T B W & d_{\mathrm{w}} \\ \text { Mineral } & m & M & d_{\mathrm{m}} \\ & W=f+p+t b w+m, \\ & \\ & & \\ & \end{array}$

then

and

$$
V=\frac{f}{d_{\mathrm{f}}}+\frac{p}{d_{\mathrm{p}}}+\frac{t b w}{d_{\mathrm{w}}}+\frac{m}{d_{\mathrm{m}}}
$$

If measurements of $W, V$ and $t b w$ are made on two occasions and changes indicated by $\Delta$, then from eqn (3) and assuming $\Delta m=0$

$$
\Delta V=\frac{\Delta f}{d_{\mathrm{f}}}+\frac{\Delta p}{d_{\mathrm{p}}}+\frac{\Delta t b w}{d_{\mathrm{w}}} .
$$

Substituting $\Delta p=\Delta W-\Delta f-\Delta t b w$ derived from eqn (1) and collecting terms :

rearranging :

$$
\Delta V=\frac{d_{\mathrm{p}}-d_{\mathrm{f}}}{d_{\mathrm{p}} d_{\mathrm{f}}} \Delta f+\frac{d_{\mathrm{p}}-d_{\mathrm{w}}}{d_{\mathrm{p}} d_{\mathrm{w}}} \Delta t b w+\frac{\Delta W}{d_{\mathrm{p}}}
$$

$$
\Delta f=\frac{d_{\mathrm{p}} d_{\mathrm{f}}}{d_{\mathrm{p}}-d_{\mathrm{f}}} \Delta V-\frac{\left(d_{\mathrm{p}}-d_{\mathrm{w}}\right) d_{\mathrm{f}}}{\left(d_{\mathrm{p}}-d_{\mathrm{f}}\right) d_{\mathrm{w}}} \Delta t b w-\frac{d_{\mathrm{f}}}{d_{\mathrm{p}}-d_{\mathrm{f}}} \Delta W .
$$

When the traditional values for tissue density, $d_{\mathrm{p}}=1.340, d_{\mathrm{f}}=0.900$ and $d_{\mathrm{w}}=0.993$, are inserted (Siri, 1961), we obtain:

$$
\Delta f=2 \cdot 741 \Delta V-0 \cdot 7148 \Delta t b w-2 \cdot 046 \Delta W
$$

Thus the change in weight of fat is expressed in terms of changes in body volume and the weights of body water and the body.

Similarly, returning to eqn (4) and substituting from eqn (1) $\Delta f=\Delta W-\Delta p-\Delta t b w$, an expression for $\Delta p$, the change in protein weight, can be derived giving

$$
\Delta p=3 \cdot 046 \Delta W-0 \cdot 2852 \Delta t b w-2 \cdot 741 \Delta V
$$

\section{DISCUSSION}

Bone mineral mass has been assumed to remain unaffected by body-weight changes for the purpose of generating this model. Observations of bone loss from astronauts who spent 12 weeks in a weightless state have shown an average bone mineral loss of $0.33 \%$ week from the normally weight-bearing os calcis but no significant loss from the radius or ulna (Vogel $\&$ Whittle, 1976). No literature has been found, however, to document changes in bone mass associated with simple energy imbalance. Parfitt (1983) has reported that during growth, bone is deposited at a rate equivalent to $0.06-0.12 \%$ adult bone mass/week, while in post-menopausal osteoporosis average rates of loss equivalent to $0.02 \%$ week are found. These rates of change of bone mass contrast with rates of loss of body-weight of $3 \% /$ week 
observed by Kinney et al. (1968) in surgical patients and gains of $2 \%$ /week found in the overfeeding studies of Passmore et al. (1955). It therefore seems unlikely that bone mineral mass will respond, to any great extent, to short- or medium-term changes in body-weight.

Body-weight can now be measured with a precision of $1 \mathrm{~g}$ using integrating electronic force platforms; however, the body-weight measurements cannot be made at the same time as the under-water weight observations usually used in calculating volume or density. Respiratory water losses of about $0.5 \mathrm{~g} / \mathrm{min}$ and a net loss of about $0.1 \mathrm{~g} / \mathrm{min}$ in respiratory gas exchange reduce the confidence in estimates of weight at the time of volume estimation to perhaps $10 \mathrm{~g}$. From a review of techniques (Burkinshaw, 1985) the precision of density estimates has been reported as being typically $0.0023 \mathrm{~kg} / \mathrm{l}^{3}$ and that of total body water estimates $1 \mathrm{~kg}$ using ${ }^{3} \mathrm{H}_{2} \mathrm{O}$ dilution. In our experience the precision claimed for densitometry is realistic, and using ${ }^{2} \mathrm{H}_{2} \mathrm{O}$ dilution (Schoeller et al. 1980) we find a value of $2 \%$ of body water. This represents about $0.8 \mathrm{~kg}$ for a lean $70 \mathrm{~kg}$ subject.

Taking volume $=W / d$, and applying analysis of error propagation:

$$
\sigma_{\mathrm{v}}^{2}=\frac{1}{d^{2}} \times \sigma_{\mathrm{w}}^{2}+\frac{W^{2}}{d^{4}} \times \sigma_{\mathrm{d}}^{2} .
$$

Substituting $\sigma_{\mathrm{w}}=0.01 \mathrm{~kg}, \sigma_{\mathrm{d}}=0.0023 \mathrm{~kg} / 1, d=1$ and $W=70 \mathrm{~kg}$; then $\sigma_{\mathrm{v}}=0.161$ litres.

Summing the variances due to volume, water and weight,

$$
\begin{aligned}
\sigma_{\Delta \mathrm{P}}^{2} & =2\left[(2.741 \times 0.161)^{2}+(0.7148 \times 0 \cdot 8)^{2}+(2.046 \times 0.01)^{2}\right] \mathrm{kg}^{2} \\
& =2[0.195+0.327+0.0004] \mathrm{kg}^{2} .
\end{aligned}
$$

Hence the precision of fat-change estimates, $\sigma_{\Delta \mathrm{f}}$, is $1.02 \mathrm{~kg}$.

The largest contribution to this is imprecision in total body water measurements. The corresponding precision of protein change estimates, $\sigma_{\Delta p}$, is $0.70 \mathrm{~kg}$, limited by the precision of density measurements.

If fat changes were estimated from density alone using the formula of Siri (1961): fat fraction $=(4.95 / d)-4.50$, variability in density measurements would limit the precision, $\sigma_{\Delta \mathrm{f}}$, to $1.07 \mathrm{~kg}$. By total body water alone, assuming $72.5 \%$ lean body hydration, $\sigma_{\Delta \mathrm{f}}$ would be $1.56 \mathrm{~kg}$ and the precision of protein-change estimates, $\sigma_{\Delta \mathrm{n}}$, would be $0.43 \mathrm{~kg}$. Errors resulting from changes in fat-free body composition would be additional to these imprecision estimates.

The practical validation of body composition models is notoriously difficult, especially when absolute composition values are required. Models for estimating composition change can, however, be tested by careful nutrient and energy balance studies. Continuous wholebody calorimetry measurements during a period of over- or underfeeding would provide a suitable reference, as would a carbon-nitrogen balance, using the double-labelled water technique to measure C loss. Such studies, however, have not yet been reported. However, Garrow et al. (1979) have compared fat loss estimates in obese subjects made by a variety of techniques including energy balances, and Kinney et al. (1968) have carefully analysed the composition of weight lost after surgery using balance techniques to quantify protein, fat and water losses. The findings of Kinney et al. (1968) have been used by Burkinshaw (1985) to demonstrate the changes which might realistically occur if a hypothetical $70 \mathrm{~kg}$ subject lost $4.2 \mathrm{~kg}$ of his body-weight. Table 1 compares these changes with predictions by the density and total body water models. Density measurements would overestimate fat loss threefold, while total body water would show a net gain of fat. The loss of protein indicated by total body water would be a threefold overestimate. It can be seen that our 
Table 1. Composition change estimated from density*, weight of total body water $\dagger$ (tbw) and our three-element model

\begin{tabular}{|c|c|c|c|c|c|c|}
\hline & $\begin{array}{c}\text { Initial } \\
\text { weight } \\
(\mathrm{kg})\end{array}$ & $\begin{array}{c}\text { Final } \\
\text { weight } \neq \\
(\mathrm{kg})\end{array}$ & $\begin{array}{c}\text { Change } \\
(\mathrm{kg})\end{array}$ & $\begin{array}{c}\text { Density } \\
(\mathrm{kg})\end{array}$ & $\begin{array}{l}t b w \\
(\mathrm{~kg})\end{array}$ & $\begin{array}{c}\text { Three- } \\
\text { element } \\
\text { model } \\
(\mathrm{kg})\end{array}$ \\
\hline Water & $40 \cdot 9$ & 37.7 & $3 \cdot 2$ & & & \\
\hline Protein & 120 & 11.6 & 0.4 & & 1.21 & 0.40 \\
\hline Mineral & $3 \cdot 6$ & $3 \cdot 6$ & $0 \cdot 0$ & & & \\
\hline Fat & $13 \cdot 5$ & 12.9 & 0.6 & 1.82 & -0.21 & 0.60 \\
\hline Total & $70 \cdot 0$ & $65 \cdot 8$ & $4 \cdot 2$ & & & \\
\hline $\begin{array}{c}\text { Density } \\
(\mathrm{kg} / \mathrm{l})\end{array}$ & 1.0551 & 1.0586 & & & & \\
\hline
\end{tabular}

* Fat $=$ weight $\times[(4 \cdot 95 /$ density $)-4 \cdot 50]$.

$\dagger$ Assumes fat-free body is $72.5 \%$ hydrated.

$\ddagger$ Values from Burkinshaw (1985) by kind permission of Plenum Publishing Corp.

model yields accurate measurements of fat and protein changes and does so without loss of analytical precision.

We believe that this method offers a real improvement in the accuracy with which fat and protein changes can be estimated and we hope that it will be adopted by the nutrition research community.

\section{REFERENCES}

Burkinshaw, L. (1985). Measurement of human body composition in vivo. Progress in Medical Radiation Physics 2, 113-137.

Garrow, J. S., Stalley, S., Diethelm, R., Pittet, Ph., Hesp, R. \& Halliday, D. (1979). A new method for measuring the body density of obese adults. British Journal of Nutrition 42, 173-183.

Kinney, J. M., Long, C. L., Gump, F. E. \& Duke, J. H. (1968). Tissue composition of weight loss in surgical patients. Annals of Surgery 168, $459-474$.

Parfitt, A. M. (1983). Dietary risk factors for age-related bone loss and fractures. Lancet ii, 1181-1185.

Passmore, R., Meiklejohn, A. P., Dewar, A. D. \& Thow, R. K. (1955). Energy utilisation in overfed thin young men. British Journal of Nutrition 9, 20-27.

Schoeller, D. A., van Santen, E., Peterson, D. W., Dietz, W., Jaspan, J. \& Klein, P. D. (1980). Total body water measurement in humans with ${ }^{18} \mathrm{O}$ and ${ }^{2} \mathrm{H}$ labeled water. American Journal of Clinical Nutrition 33, 2686-2693.

Siri, W. E. (1961). Body composition from fluid spaces and density: analysis of methods. In Techniques for Measuring Body Composition, pp. 223-244 [J. Brozek and A. Henschel, editors]. Washington, DC: National Academy of Sciences/National Research Council.

Vogel, J. M. \& Whittle, M. W. (1976). Bone mineral content changes in the Skylab astronauts. American Journal of Roentgenology 126, 1296-1297. 